\title{
DIGITALISASI KEUANGAN UKM \\ (Studi Kasus CV. Madu Mekar Purwakarta)
}

\section{Pandena Kicky Basuki Putri}

Teknik Industri,Sekolah Tinggi Teknologi Wastukancana

pandena.kicky@stt-wastukancana.ac.id

\section{Darmawan Yudhanegara}

Teknik Industri,Sekolah Tinggi Teknologi Wastukancana darmawan@stt-wastukancana.ac.id

\section{Rizki Fadilah}

Teknik Industri,Sekolah Tinggi Teknologi Wastukancana rizkifadilah7@gmail.com

\begin{abstract}
The Small and Medium Enterprises is plays an active role in efforts to rapidly increase business operations. The effort he does is to use technological devices to simplify the operational process in finance. This study aims to compare manual calculations with existing technology. Usually every activity to reporting manually is hard to count, make it expense time to operates business, since business's unit should focus on lift up the profitability. The use of technology has a speed of completing financial statements and income statements of only 20 minutes, with an internet credit quota of IDR. 35,000 per three months. Meanwhile, manual counting use requires a stationery fee of IDR. 75,000 per three months at a reporting rate of 3 hours.
\end{abstract}

Keywords: digitalization, sme, tahu sumedang.

$\triangle$ Corresponding author:

Email Address :darmawan@stt-wastukancana.ac.id(Purwakarta, Jawa Barat)

Received 15 April 2021, Accepted 15 Agustus 2021, Published 22 Agustus 2021

\section{PENDAHULUAN}

Kota Purwakarta merupakan daerah yang dilintasai antara Bandung dan Jakarta. Kota ini dipenuhi dengan kawasan industri yang merupakan salah satu kawasan terbesar yang ada di Jawa Barat. Sosial masyarakat tidak bisa mengenyam penghasilan sebagai karyawan industri, namun juga ada beberapa masyarakat mendapat penghasilannya dari berdagang sebagai tradisi kedaerahan.

Digitalisasi terhadap dunia usaha dan dunia industri baik produksi maupun jasa sudah menunjukan strategi dalam mengintegrasikan semua sistem perusahaan baik kecil maupun besar. Sistem ini dapat dipergunakan secara terus-menerus berkesinambungan tergantung dari sistem digital yang dibangun, sehingga dikembangkan mengikuti perubahan kebutuhan waktu ke waktu. Sedangkan peranan digital pada UKM masih relatif rendah dari sistem yang belum bisa menyesuaikan dengan pemilik UKM dan ruang lingkup sistem usaha sebagai stretegi.

CV. Kadu Mekar Purwakarta (MMP) merupakan unit usaha kecil dan menengah dalam bidang perdagangan tahu dari sumedang. Laporan yang dilakukan setiap hari sebagai catatan dilakukan secara manual, terkadang susunannya masih tidak tertata dengan baik. Semua variabel - variabel baik biaya dan pendapatan masih menggunakan ingatan oleh orang yang menyusun keuangannya, sehingga tidak semuanya bisa tersusun.

UMKM ini memiliki tujuan untuk bisa mengelola kebutuhan keuangannya dengan cepat dan rapih. Kendala yang dihadapi masih belum bisa membangun sistem pelaporan yang tepat. Sistem pelaporan keuangan ini 
diharapkan dapat menyusun laporan keuangan dengan cepat dan efisien.

\section{METODOLOGI PENELITIAN}

Metodologi yang digunakan untuk penelitian ini adalah metode perbandingan secara manual dengan secara digital terhadap sistem pelaporan keuangan rugi laba pada studi kasus penelitian ini. Metodogi penelitian sebagai berikut:

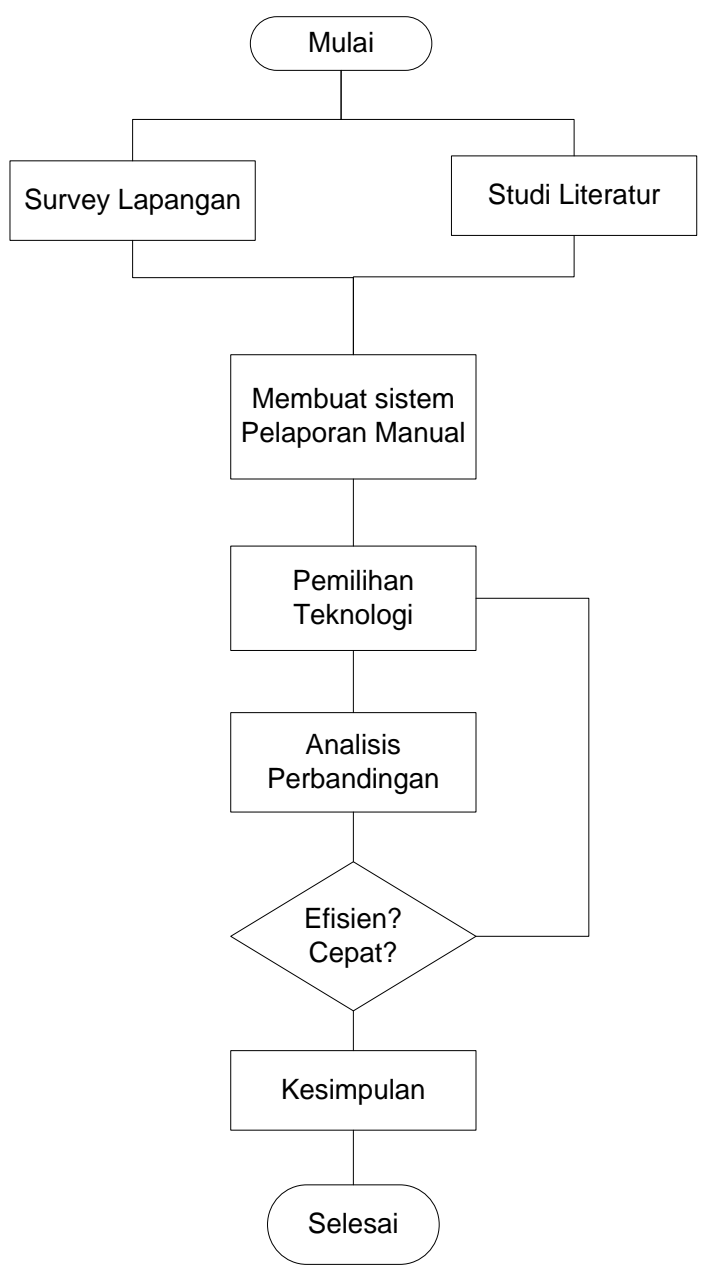

Gambar 1. Metodologi Penelitian

\section{Survey Lapangan}

Penelitian ini memilih objek kajian terhadap sistem pelaporan keuangan yang dimiliki oleh dunia usaha kecil yang sering ditemukan pada usaha yang ada di kota. Produk tahu sumedang menjadi kajian lapangan dalam digitalisasi keuangan.

\section{Studi Literatur}

Penelitian ini didasari oleh jurnal penelitian terdahulu yang memiliki karakteristik yang sama. Jurnal yang digunakan berdasarkan pada penggunaan teknologi informasi yang digunakan pada sistem yang memiliki ruang lingkup yang kecil untuk suatu unit usaha.Laporan laba rugi single step adalah laporan keuangan yang menyajikan pendapatan, pengeluaran, dan pada akhirnya laporan laba atau rugi yang dihasilkan oleh bisnis, tetapi laporan ini hanya melaporkan informasi dengan menggunakan hanya satu persamaan untuk menghitung laba.

\section{Sistem Pelaporan Manual}

UKM telah melakukan pelaporan keuangan dengan metode single step. Metode ini sangat sederhana dan efektif untuk sistem pelaporan perdagangan yang ada di MMP. Sistem pelaporannya yaitu dengan menentukan beban biaya dan pendapatannya, disesuaikan berdasarkan aktual yang telah dilakukan terakhir. Karena memudahkan setiap waktu melihat hasil keuangan saat itu juga, namun belum bersifat "real time". Sistem pelaporan manual ini yang manjadi dasar untuk perbaikan.

\section{Pemilihan Teknologi}

Teknologi yang digunakan merupakan teknologi yang sudah ada dan mudah diunduh di toko penyedia digital. Teknologi yang dipilih merupakan teknologi yang memiliki sifat karakteristik serta variabel biaya dan variabel pendapatan dengan yang ada di sistem pelaporan manual. Salah satu pendekatan pemilihan teknologi bisa dilakukan secara dinamis tergantung kebutuhan yang disusuaikan dengan pengguna teknologi.

\section{Analisis Perbandingan}

Analisis dalam penelitian ini yaitu adanya perbedaan antara sistem manual dengan sistem digital. Analisis ini dilakukan dengan cara melihat hasil yang telah dilakukan secara manual dengan setelah diterapkan teknologi digital pada periode tertentu sesuai kajian.

\section{Hasil Perbandingan}

Setelah dilakukan perbandingan, perlu dilakukan selisih dari hasil keduanya. Jika memiliki nilai positif maka sistem yang baru efektif untuk digunakan. Namun, jika nilai negatif maka perlu dilakukan pemilihan teknologi kembali. Teknologi yang digunakan dapat menghasilkan adanya pengurangan waktu proses bisnis dalam penangan keuangan lebih 
PandenaK.B.P., Darmawan Y. \&Rizki F./Digitalisasi Keuangan UKM..........

cepat, sehingga proses bisnis dapat tidak terganggu dengan adanya laporan yang tidak teratur dan tidak tepat waktu. Penelitian ini tujuannya untuk memperoleh teknologi yang efektif sesuai dengan sistem pelaporan yang dijalankan di MPP, sehingga memperlancar proses bisnis dengan adanya laporan keuangan yang cepat dan akurat.

\section{HASIL}

\section{Kajian Penelitian}

Laporan laba rugi yang dilakukan oleh MPP dilakukan secara manual. Laporan yang dilakukan secara harian, mingguan, dan bulanan. Pasar yang tengah dijalankan yaitu untuk pemasaran daerah Bendul, Pasar Senen, dan Pasar Rebo. Masing - masing laporan laba rugi dilakukan untuk satu laporan dari ketiga lokasi pemasaran di atas.

\section{Tabel 1. Jumlah Produksi per Papan}

\begin{tabular}{|c|c|}
\hline Tanggal & Jumlah (Papan) \\
\hline $01 / 03 / 2021$ & 175 \\
\hline $02 / 03 / 2021$ & 185 \\
\hline $03 / 03 / 2021$ & 215 \\
\hline $04 / 03 / 2021$ & 205 \\
\hline $05 / 03 / 2021$ & 210 \\
\hline $06 / 03 / 2021$ & 200 \\
\hline $07 / 03 / 2021$ & 180 \\
\hline $08 / 03 / 2021$ & 186 \\
\hline $09 / 03 / 2021$ & 200 \\
\hline $10 / 03 / 2021$ & 190 \\
\hline $11 / 03 / 2021$ & 200 \\
\hline $12 / 03 / 2021$ & 185 \\
\hline $13 / 03 / 2021$ & 210 \\
\hline $14 / 03 / 2021$ & 205 \\
\hline $15 / 03 / 2021$ & 180 \\
\hline $16 / 03 / 2021$ & 220 \\
\hline $17 / 03 / 2021$ & 200 \\
\hline $18 / 03 / 2021$ & 195 \\
\hline $19 / 03 / 2021$ & 190 \\
\hline $20 / 03 / 2021$ & 200 \\
\hline $21 / 03 / 2021$ & 200 \\
\hline $22 / 03 / 2021$ & 185 \\
\hline $23 / 03 / 2021$ & 190 \\
\hline $24 / 03 / 2021$ & 200 \\
\hline $25 / 03 / 2021$ & 180 \\
\hline & \\
\hline
\end{tabular}

\begin{tabular}{|c|c|}
\hline Tanggal & Jumlah (Papan) \\
\hline $26 / 03 / 2021$ & 200 \\
\hline $27 / 03 / 2021$ & 210 \\
\hline $28 / 03 / 2021$ & 220 \\
\hline $29 / 03 / 2021$ & 207 \\
\hline $30 / 03 / 2021$ & 200 \\
\hline $31 / 03 / 2021$ & 185 \\
\hline Total & 5,923 \\
\hline
\end{tabular}

Sumber: data diolah, 2021

Pengumpulan data dilakukan secara langsung pada laporan keuangan yang ada. Data ini tidak langsung dapat dioleh dengan metode single step, sehingga perlu tambahan data dengan melakukan wawancara terhadap karyawan yang menanganinya secara langsung. Sistem pelaporan manual yang dilakukan tersusun dari perhitungan manual untuk setiap beban produksi dan pendapatan yang tercatat oleh bagian sales, sedangkan untuk beban produksinya sebagai berikut:

Tabel 2. Kebutuhan Biaya

\begin{tabular}{|l|l|l|}
\hline Aktivitas & Kebutuhan & periode \\
\hline $\begin{array}{l}\text { Membeli kacang } \\
\text { kedela }\end{array}$ & 2 ton & $\begin{array}{l}\text { per } \\
\text { minggu }\end{array}$ \\
\hline $\begin{array}{l}\text { Membayar gaji } \\
\text { karyawan }\end{array}$ & 9 orang & per hari \\
\hline Membayar Listrik & 1 & per bulan \\
\hline Biaya Pengiriman & 1 & per hari \\
\hline Suluh Kayu & 1 mobil & per hari \\
\hline Suluh Kayu & 50 karung & per hari \\
\hline $\begin{array}{l}\text { Membayar Sewa } \\
\text { Gedung Dan } \\
\text { Peralatan }\end{array}$ & 1 & per bulan \\
\hline Membeli Bumbu & 1 set & per hari \\
\hline
\end{tabular}

Sumber: data diolah, 2021

Pendapatan yang dimuat adalah pendapatan penjualan produk ataupun jasa yang diterima oleh perusahaan pada periode tertentu. Pada MMP hanya mendapatkan pendapatan pada penjualan produk. Berdasarkan laporan penjualan pada Tabel 3. akan disajikan hasil penjualan papan per harian selama Bulan Maret 2021 dengan harga satuan Rp 38.000,- 
JRE: Jurnal Riset Entrepreneurship-Volume 4Nomor 2, Agustus 2021; 1-8

Tabel 3. Pendapatan Penjualan Papan Harian per Bulan

\begin{tabular}{|c|c|c|c|}
\hline Tanggal & $\begin{array}{c}\text { Jumlah } \\
\text { (Papan) }\end{array}$ & $\begin{array}{c}\text { Harga } \\
\text { (Rp) }\end{array}$ & $\begin{array}{c}\text { Pendapatan } \\
\text { (Rp) }\end{array}$ \\
\hline $01 / 03 / 2021$ & 175 & 38,000 & 6.650 .000 \\
\hline $02 / 03 / 2021$ & 185 & 38,000 & 7.030 .000 \\
\hline $03 / 03 / 2021$ & 180 & 38,000 & 6.840 .000 \\
\hline $04 / 03 / 2021$ & 205 & 38,000 & 7.790 .000 \\
\hline $05 / 03 / 2021$ & 165 & 38,000 & 6.270 .000 \\
\hline $06 / 03 / 2021$ & 200 & 38,000 & 7.600 .000 \\
\hline $07 / 03 / 2021$ & 180 & 38,000 & 6.840 .000 \\
\hline $08 / 03 / 2021$ & 186 & 38,000 & 7.068 .000 \\
\hline $09 / 03 / 2021$ & 200 & 38,000 & 7.600 .000 \\
\hline $10 / 03 / 2021$ & 190 & 38,000 & 7.220 .000 \\
\hline $11 / 03 / 2021$ & 200 & 38,000 & 7.600 .000 \\
\hline $12 / 03 / 2021$ & 185 & 38,000 & 7.030 .000 \\
\hline $13 / 03 / 2021$ & 175 & 38,000 & 6.650 .000 \\
\hline $14 / 03 / 2021$ & 205 & 38,000 & 7.790 .000 \\
\hline $15 / 03 / 2021$ & 180 & 38,000 & 6.840 .000 \\
\hline $16 / 03 / 2021$ & 205 & 38,000 & 7.790 .000 \\
\hline $17 / 03 / 2021$ & 200 & 38,000 & 7.600 .000 \\
\hline $18 / 03 / 2021$ & 195 & 38,000 & 7.410 .000 \\
\hline
\end{tabular}

\begin{tabular}{|c|c|c|r|}
\hline Tanggal & $\begin{array}{c}\text { Jumlah } \\
\text { (Papan) }\end{array}$ & $\begin{array}{c}\text { Harga } \\
\text { (Rp) }\end{array}$ & $\begin{array}{c}\text { Pendapatan } \\
\text { (Rp) }\end{array}$ \\
\hline $19 / 03 / 2021$ & 190 & 38,000 & 7.220 .000 \\
\hline $20 / 03 / 2021$ & 180 & 38,000 & 6.840 .000 \\
\hline $21 / 03 / 2021$ & 200 & 38,000 & 7.600 .000 \\
\hline $22 / 03 / 2021$ & 185 & 38,000 & 7.030 .000 \\
\hline $23 / 03 / 2021$ & 173 & 38,000 & 6.574 .000 \\
\hline $24 / 03 / 2021$ & 200 & 38,000 & 7.600 .000 \\
\hline $25 / 03 / 2021$ & 180 & 38,000 & 6.840 .000 \\
\hline $26 / 03 / 2021$ & 200 & 38,000 & 7.600 .000 \\
\hline $27 / 03 / 2021$ & 210 & 38,000 & 7.980 .000 \\
\hline $28 / 03 / 2021$ & 170 & 38,000 & 6.460 .000 \\
\hline $29 / 03 / 2021$ & 165 & 38,000 & 6.270 .000 \\
\hline $30 / 03 / 2021$ & 200 & 38,000 & 7.600 .000 \\
\hline $30 / 03 / 2021$ & 185 & 38,000 & 7.030 .000 \\
\hline Total & 5,664 & 38,000 & 215.232 .000 \\
\hline \multicolumn{3}{|c}{ Total } & 215.232 .000 \\
\hline
\end{tabular}

Sumber: data diolah, 2021

Pengeluaran dapat dilihat pada Tabel 4. di bawah ini, sedangkan pengeluaran usaha dapat dilihat kolom aktivitas dan juga berapa banyak kuantitas pembelanjaan barang.

Tabel 4. Biaya Per Satuan

\begin{tabular}{|c|l|c|c|c|c|c|}
\hline No & \multicolumn{1}{|c|}{ Aktivitas } & Jumlah & $\begin{array}{c}\text { Periode } \\
\text { Bayar }\end{array}$ & $\begin{array}{c}\text { Harga } \\
(\mathrm{Rp})\end{array}$ & Pengeluaran & $\begin{array}{c}\text { Total Bayar } \\
\text { / Bulan }\end{array}$ \\
\hline 1 & Membeli Kacang Kedelai & 2 ton & per mgg & $7.000 / \mathrm{kg}$ & 7.000 .000 & 28.000 .000 \\
\hline 2 & Membeli Suluh Serut & $\begin{array}{c}50 \\
\text { karung }\end{array}$ & per mgg & $\begin{array}{c}30.000 / \\
\text { karung }\end{array}$ & 10.500 .000 & 45.000 .000 \\
\hline 3 & Membeli Suluh Kayu & 1 truk & per mgg & $\begin{array}{c}1.500 .000 / \\
\text { truk }\end{array}$ & 10.500 .000 & 45.000 .000 \\
\hline 4 & $\begin{array}{l}\text { Membayar Sewa Gedung } \\
\text { Dan Peralatan }\end{array}$ & 1 set & per bln & 20.000 .000 & 20.000 .000 & 20.000 .000 \\
\hline 5 & Membayar Gaji Karyawan & & & & & \\
\hline $5 . \mathrm{a}$ & $\begin{array}{l}\text { Bagian Pencucian Dan } \\
\text { Penggilingan }\end{array}$ & 2 & per hari & 90.000 & 105.000 & 3.150 .000 \\
\hline $5 . b$ & $\begin{array}{l}\text { Bagian Perebusan Dan } \\
\text { Penyaringan }\end{array}$ & 2 & per hari & 86.000 & 100.000 & 3.000 .000 \\
\hline $5 . c$ & $\begin{array}{l}\text { Bagian Cetak Dan } \\
\text { Pemotongan }\end{array}$ & 2 & per hari & 84.000 & 90.000 & 2.700 .000 \\
\hline $5 . d$ & Bagian Penggorengan & 2 & per hari & 80.000 & 84.000 & 2.520 .000 \\
\hline 6 & $\begin{array}{l}\text { Biaya Pengiriman Produk, } \\
\text { Bahan Baku }\end{array}$ & 1 & $\begin{array}{c}\text { per } \\
\text { minggu }\end{array}$ & 250.000 & 1.750 .000 & 7.500 .000 \\
\hline 7 & Tagihan Listrik & 1 & per bulan & $1,000.000$ & 1.000 .000 & 1.000 .000 \\
\hline 8 & Membeli Bumbu & 1 set & per hari & 250.000 & 250.000 & 7.500 .000 \\
\hline 9 & Biaya Lainnya & 1 & per bulan & $1,000.000$ & 1.000 .000 & 1.000 .000 \\
\hline & \multicolumn{1}{|c|}{ Jumlah } & & & & & 166.370 .000 \\
\hline
\end{tabular}

Sumber: data diolah, 2021 
Bahwa dalam Tabel 4. memperlihatkan laporan laba rugi secara manual yakni biaya yang dimuat merupakan segala biaya yang dikeluarkan oleh UKM untuk keperluan produksi selama periode tertentu yaitu selama satu bulan penuh untuk tiga lokasi pemasaran. Biaya-biaya tersebut terbagi menjadi beberapa kategori sebagai berikut :

Tabel 5. Biaya Per Satuan CV. MADU MEKAR PURWAKARTA Laporan Laba Rugi (Periode Maret 2021)

\begin{tabular}{|c|l|r|}
\hline \multicolumn{2}{|c|}{ Pendapatan : } & Rp. \\
\hline 1 & Pendapatan Penjualan & \multicolumn{1}{c|}{$215,232,000$} \\
\hline 2 & Pendaptan Jasa & - \\
\hline 3 & Total Pendapatan & $215,232,000$ \\
\hline \multicolumn{2}{|c|}{ Biaya : } \\
\hline 1 & Biaya Bahan Baku & $35,500,000$ \\
\hline 2 & Biaya Bahan Bakar & $90,000,000$ \\
\hline 3 & Biaya Sewa & $20,000,000$ \\
\hline 4 & Biaya gaji & $11,370,000$ \\
\hline 5 & Biaya Transport & $7,500,000$ \\
\hline 6 & Biaya Listrik & $1,000,000$ \\
\hline 7 & Biaya Lainnya & $1,000,000$ \\
\hline 8 & Total Biaya & $166,370,000$ \\
\hline \multicolumn{2}{|c|}{ Laba : } & $48,862,000$ \\
\hline
\end{tabular}

Sumber: data diolah, 2021

\section{PEMBAHASAN}

Walaupun hasil akhir laporan secara manual masih terdapat kekurangan, karena terbatasnya informasi dan pengendalian keuangan yang diperoleh tetapi kurang lebihnya bentuk laporan laba rugi untuk dijadikan laporan yang dapat selanjutnya dianalisis. Dengan dibuatnya laporan tersebut akan memberikan beberapa kemudahan untuk kedepannya terutama dalam perencanaan perolehan laba ataupun perencanaan produksi. Dan selain itu juga UKM juga menggunakan Laporan Laba Rugi sebagai acuan target atau strategi untuk bulanbulan berikutnya.

\section{Digitalisasi}

Teknologi saat ini banyak menawarkan secara gratis maupun berbayar dengan mudah diperoleh, namun tidak semua cocok dengan sistem yang akan diterapkan, baik pengguna maupun keadaan sistem bisnis nyata. Setelah dilakukan pemilihan teknologi, dengan melihat variabel-variabel yang ada di MMP serta aplikasi dalam fitur tersebut, sesuai dengan jumlahnya, tampilan layarnya, serta kemudahan operasi pengguna, maka aplikasi buku warung ini yang paling sesuai digunakan di MMP dibandingkan dengan aplikasi jubelio dan BukuKas, variabel selain lebih komplek dan penggunanya tidak mudah (user friendly) bagi MMP, sehingga penerapan teknologi informasi pada UKM ini cenderung lebih cocok pada aplikasi buku warung.

Aplikasi buku warung ini didirikan oleh Abhinay Peddisetty dan Chinmay Chauhan pada akhir tahun 2019. Mereka keduanya masih bekerja di Carousell, sebelumnya mereka berdua pernah meniti karier di Grab, Belong, dan Near. Selama hidup 15 tahunnya mereka aktif terus mengembangkan aplikasi bidang layanan pembayaran dan finansial untuk segmen UKM di Indonesia dan Asia Tenggara. Buku warung adalah sebuah aplikasi catatan keuangan harian dan pembukuan usaha UMKM untuk mencatat keuntungan penjualan transaksi bisnis.Mulai dari pemasukan dan pengeluaran, hutang dan piutang pelanggan. Bahkan juga bisa membuat laporan keuangan usaha dengan sangat mudah. Aplikasi ini bisi di unduh melalui penyedia toko digital secara gratis pada pelayan toko (playstore) berbasis android yang cukup banyak digunakan pengguna seluler.

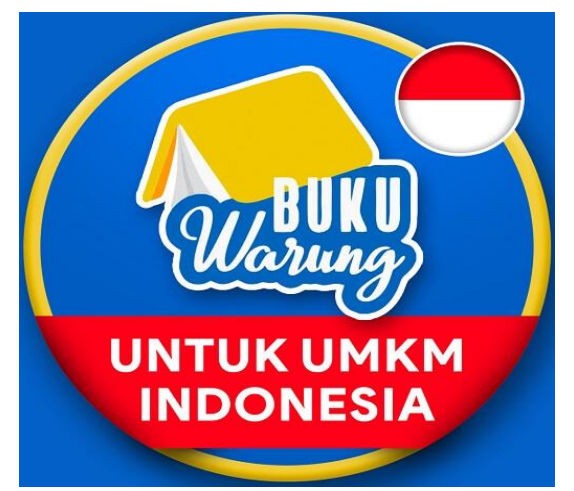

Gambar 2. Teknologi yang digunakan

Teknologi yang digunakan dalam penelitian ini adalah buku warung, fitur yang dimiliki aplikasi ini adalah :

1. Data - data tersimpan pada cloud secara aman. Data pengguna disimpan dalam server penyedia aplikasi, sehingga secara pemulihan data bisa dilakukan kapan saja dan dimana saja.

2. Bagi pengguna yang memiliki pembukuan yang berbeda-beda, karena adanya kepemilikan lebih dari satu bisni, atau pembukuan yang bisa diatur personalisasi 
pribadi yang artinya menambahkan pembukuan lebih dari satu, bisa menggunakan cara memisahkan buku arus, yakni arus kas berbeda agar usaha makin maju dan mudah bagi penggunanya.

3. Aplikasi ini cukup interaktif, dapat mengingatkan kepada pengguna mengenai konsumen memiliki tagihan hutang secara otomatis, melalui SMS atau WhatsApp yang sudah terdaftar pada aplikasi, kepada pelanggan dengan gratis dengan fitur ini.

4. Selain laporan, apikasi ini berperan sebagai komputasi kasir, maksudnya apabila pelanggan membutuhkan mesin kasir namun tidak praktis, maka aplikasi buku warung bisa membantu menggantikannya. Bukti transaksi dapat dicetak berupa resi konsumen, melalui bluetooth printer.

5. Selama data diinput saat bersamaan, maka aplikas secara cepat akurat menyusun laporan keuangan baik harian, mingguan, bulanan bahkan tahunan tanpa penyusunan seperti manual yang dilakukannya. Sedangkan laporan dapat langsung diunduh dengan mudah.

6. Aplikasi ini dirancang secara umum untuk jenis laporan dan sesuai dengan pengguna unit usaha berskala kecil, sehingga memungkinkan dapat diterapkan diberbagai jenis usaha kecil dan menengah

\section{Cara Penggunaan Aplikasi}

MMP melakukan penerapan teknologi berdasarkan fitur aplikasi yang dimiliki serta disesuaikan dengan data usaha yang ada. Fitur ini yang ada dalam teknologi dapat memudahkan dalam membuat laporan keuangan secara teori, cara - caranya sebagaimana berikut:

a. Melakukan registrasi usaha dengan menuliskan nama perusahaan sebagai profil aplikasi sesuai dengan pilihan yang tersedia.

b. Mengisi data-data yang ada di usaha kedalam aplikasi dengan menginput pada ruas yang sesuai. Secara penampilan jendela aplikasi tampak sederhana dan mudah dimengerti oleh pengguna MMP.

c. Data - data setelah di input, disimpan pada ikon yang ada dalam aplikasi, apabila terlewat maka data yang diinput tidak tersimpan pada cloud server. d. Apabila data yang ada sebagai hutang piutang, terdapat pada bagian yang otomatis antara pengeluaran berwarna hijau dengan pengeluaran berwarna merah. Seperti pada Gambar 3. di bawah ini. Termasuk data konsumen atau data transaksi.

e. Menginput data berikutnya yaitu jurnal transaksi, pemasukan dan pengeluaran. Transaksi pemasukan dan pengeluaran di tempatkan pada ruas yang berbeda.

f. Selain data pemasukan dan pengeluaran, pengguna dapat menginput data ongkos internal operasi usaha. Data internal operasi disesuaikan dengan kondisi usaha yang berhubungan dengan biaya langsung dan tak langsung.

g. Data - data yang telah diinput dan disimpan, apabila terjadi kesalahan atau pemeriksaan baik nominal mapun waktu input maka dapat dilihat dengan jelas dan mudah.

h. Aplikasi ini bersifat dapat dipergunakan secara mobilitas, sehingga cukup praktis bagi pengguna yang memiliki usaha yang mobilitasnya cukup banyak, sehingga dapat dikendalikan dimanapun dan kapanpun.

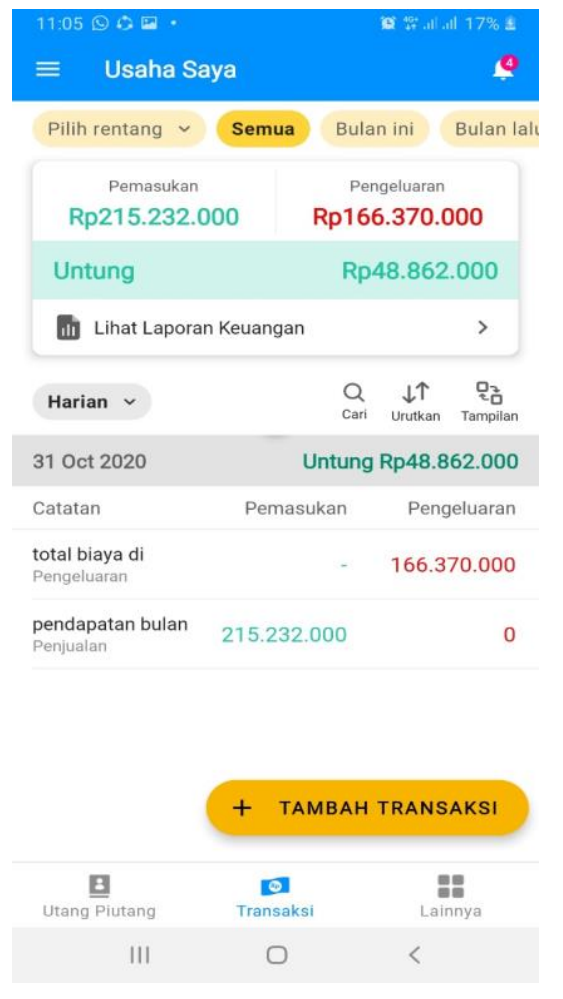

Gambar 3. Laporam Rugi Laba Digital 
Penelitian ini menghasilkan analisis terhadap pengguna teknologi terutama UKM yang masih kurang dalam mengenal teknologi. Bagi peneliti melihat bahwa teknologi seperti ini tidak mudah digunakan bagi usahawan, seperti: pemilik UKM yang tingkat pendidikannya rendah, berbeda dengan pengguna yang memiliki tingkat pendidikannya cukup.

1. Analisis laporan harian.

Penyusunan Laporan harian memerlukan satu buah buku besar (Rp 25.000/ 100 lembar) tambahan yang akan digunakan satu lembar per laporan, dan menghabiskan waktu kurang lebih 15 menit per hari untuk menyusunnya.

2. Analisis laporan mingguan.

Penyusunan laporan mingguan memerlukan satu buah buku besar (Rp 25.000/100 lembar) tambahan yang akan digunakan satu lembar per laporan, dan menghabiskan waktu kurang lebih 30 menit per minggu untuk menyusunnya.

3. Analisis laporan keseluruhan.

Penyusunan laporan laba rugi memerlukan satu buah buku besar (Rp 25.000/ 100 lembar) tambahan ang akan digunakan satu lembar per laporan, dan menghabiskan waktu kurang lebih 40 menit per bulannya untuk menyusunnya. Apabila digabungkan untuk penyusunan ketiga laporan tersebut memerlukan biaya total Rp 75.000 per 100 hari dan waktu kurang lebih 20 menit perharinya.

4. Analisis Pengguna teknologi.

MMP merupakan unit usaha bidang tahu sumedang masih kurang mengikuti perkembangan teknologi yang ada, proses bisnis masih dilakukan secara manual untuk pelaporan keuangan. Perkenalan teknologi yang ada dari berbagai alternatif hanya satu yang memiliki kemudahaan pengguna dengan adanya pengguna mudah memahaminya serta variabel-variabel yang ada dalam aplikasi sesuai dengan variabelvariabel yang diinput dalam usahanya.

\section{KESIMPULAN}

Hasil penelitian ini selama beberapa bulan pada kajian digitalisasi keuangan untuk UKM MMP terhadap kesehatan keuangannya, maka diperoleh kesimpulan dan saran sebagai berikut

1. Menunjukan dengan penerapan teknologi informasi lebih efisien dibanding dengan sistem pelaporan manual yang sedang dijalaninnya.

2. Hasil perbandingan menunjukan bahwa dengan digitalisasi adanya penghematan sebesar Rp 35.000 per tiga bulan. Sedangkan untuk waktu kecepatan sistem pelaporan, yang biasa dilakukan dengan manual selama tiga jam sedangkan untuk perhitungan digital hanya 15 - 20 menit.

3. Penerapan digital pada UKM tidak semudah untuk menerapkan saja, namun adanya kendala dalam sosialisasi teknologi terhadap UKM yang mudah diterima oleh pengguna, sehingga perlu dilakukan penelitian ilmiah seperti melihat teknologi yang ada dengan keadaan unit usaha yang ada.

4. Sistem pelaporan dalam penelitian hanya pada dasar untuk sistem pelaporan laba rugi, namun dipersiapkan untuk laporan tahunan yang berguna untuk pengelolaan lebih luas.

5. Walaupun laporan ini hanya pada bulan maret 2021, maka penggunaan teknologi ini tidak terbatas.

\section{DAFTAR PUSTAKA}

E. Purwanti, "Analisis Pengetahuan Laporan Keuangan Pada UMKM Industri Konveksi Salatiga," Among Markati, vol. 10, no. 20, 2017.

K. A. Putri and I. Amal, "E-Perelek: Penguatan Pangan Melalui Inovasi Kebijakan Berbasis Modal Sosial dan Teknologi di Kabupaten Purwakarta, Jawa Barat," Simulacra J. Sosiol., vol. 2, no. 1, 2019, doi: $10.21107 / \mathrm{sml} . v 2 \mathrm{i} 1.5522$.

M. Ilham and M. R. Lubis, "Rancang Bangun Aplikasi Laporan Laba Rugi Pada CV . NURI Pematangsiantar," Semin. Nas. Sains Teknol. Inf., 2019.

N. Srimenganti, "Segmentasi Pasar Pembeli Tahu Sumedang (Studi Kasus pada Perusahaan Tahu Bungkeng Kabupaten Sumedang)," Mimb. AGRIBISNIS J. Pemikir. Masy. Ilm. Berwawasan Agribisnis, vol. 1, no. 2, 2017, doi: 10.25157/ma.v1i2.57.

R. Eller, P. Alford, A. Kallmünzer, and M. Peters, "Antecedents, consequences, and challenges of small and medium-sized enterprise digitalization," J. Bus. Res., vol. $112, \quad 2020, \quad$ doi: 10.1016/j.jbusres.2020.03.004. 
R. Viswanathan and A. Telukdarie, "A systems dynamics approach to SME digitalization," in Procedia Computer Science, 2021, vol. 180, doi: 10.1016/j.procs.2021.01.331.

SME Annual Report, "Digitalisation survey of SME in 2018," SME Annu. Rep., vol. 91, no. Box Article, 2018. 